\title{
Design and Implementation of University Art Education Management System Based on JAVA Technology
}

\author{
https://doi.org/10.3991/ijet.v13i10.9452 \\ Xuchun Chen \\ Chongqing Technology and Business University, Chongqing, China \\ 465658104 @qq.com
}

\begin{abstract}
Along with the popularity of teaching ideas such as quality-oriented education and comprehensive education, colleges and universities are paying more attention to the art teaching and art training of students. Besides, the rapid development of computer technology and its extensive penetration in many fields promote the $\mathrm{de}^{-}$velopment of art teaching management model towards standardization and schematizations. Therefore, a university art teaching management system based on JAVA technology is designed. The system chooses JAVA as the main programming language, eclipse as the development tool, and SSH of Open Source as the basic framework. MVC pattern is used to design the Struts architecture to ensure the data processing capability of the system, and SQL is used as the backend database to ensure the integrity of the data and the storage efficiency of the system. After testing, the system meets the expected requirements, changes the traditional university art teaching model, and enriches the dimension of art teaching. What's more, the system expands the thinking of art teaching work for teachers in colleges and universities, and also satisfies the urgent demand of university students for art training.
\end{abstract}

Keywords_-JAVA technology; Art teaching; SQL database; MVC

\section{Introduction}

As the understanding of quality-oriented education and general education deepens, more emphasis and attention have been attached to art education and teaching in colleges and universities [1-3]. At the same time, the rapid development of computer technology and penetration in many fields has made the development of university art education management progress towards the goal of scientific and standardized management [4-6]. In the process of art teaching, there will be a lot of management history documents and many multimedia documents that are labor-consuming for manual processing in ordinary work. In addition, most music and art education direction in the curriculum management and student file management are still in the experimental stage so that few schools have use the scientific educational and teaching management model [7-9]. To make the teaching management in college of art education become more systematic and standardized, it is necessary to construct the teaching management system of art education, and to provide support for teaching decision-making and management 
through network communication, computer and management knowledge, which is the key way to realize the goal of informatization of art education and teaching.

\section{$2 \quad$ Related Theory and Technology}

\subsection{B/S pattern system architecture}

As for $\mathrm{B} / \mathrm{S}$ architecture, the browser belongs to the distributed communication server of the network and the client side. Users can send the request to the server through the browser, and the server is responsible for parsing the request from the browser and then returns information to the browser [10-12]. As far as the $\mathrm{B} / \mathrm{S}$ architecture is concerned, the work of client side has been simplified. Based on this model, the software development and maintenance can be carried out only by installing the browser and the system. In terms of the server, the efficiency of system development and maintenance is significantly improved.

\subsection{Java 2 platform (enterprise edition)}

Java2 platform, as a set of technical guidelines launched by Sun Company, is to solve the compatibility problem of using information products in enterprise backend [13-15]. The specific advantages of J2EE are reflected in the following aspects. First, through the application of $\mathrm{B} / \mathrm{S}$ model, this architecture can reduce the requirements faced by the user client side, and the client side can access the backend application only based on the browser. Second, it can provide a transplantable, independent, stable and multi-user enterprise-level R\&D platform for users. The use of J2EE can simplify the application deployment process and greatly improve the R\&D efficiency.

The SSH framework is named after a lightweight framework because it does not consume too much resources in starting and running. It can also be considered that lightweight is the degree to which architecture depends on containers. If the dependency is smaller, it is necessarily lightweight [16-18]. The advantages of applying such software architecture lie in that they are less coupling and more flexible. Figure 1 shows the flow chart of using SSH.

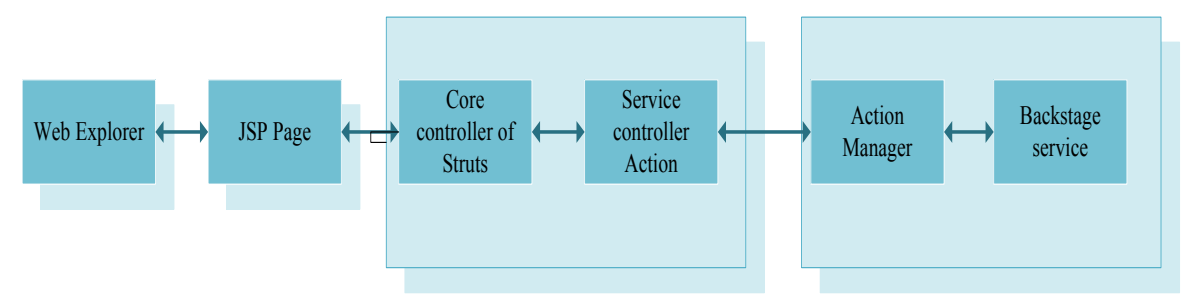

Fig. 1. System flowchart of SSH frame 


\subsection{MVC model}

Smalltalk-80GUI Labratory introduced the MVC architecture model in the 1980s. The service and presentation layers are separated, and the applicability and reusability of the MVC model are outstanding for many WAP and WEB [19-20]. The above-mentioned characteristics significantly reduce the technological content of MVC in developing and maintaining the user interface, and obviously shorten the R\&D time. The separation of the business logic layer and the presentation layer also makes it easier to modify and maintain Struts-based Web applications. MVC has been widely used in the design of interactive systems, especially in the R\&D of complex applications for its above advantages.

\section{Demand Analysis}

\subsection{System objective}

The purpose of this system is to develop the network music appreciation teaching so that the traditional boring teaching model can be improved, the teaching effect and quality can be improved. Besides, the individualized teaching can be fully carried out based on the network carrier. Through the network survey, students can enjoy music more freely so that educational burden can be reduced and educational cost will be decreased.

\subsection{Overview of system services}

The system has the following service functions:

1. User management: teachers and students are the users of this system and the activities of both will intuitively reflect the system functions.

2. Curriculum management: to release and manage the teachers' curriculum development.

3. Upload and download resources: courseware related to the course and materials are downloaded and uploaded.

4. System announcement: announcement about examination, work, and study.

5. Online testing: combined with the network, teachers will publish the tests and assignments.

6. Online communication: teachers and students can communicate based on the network.

\subsection{Analysis of system function module}

Administrator subsystem specifically involves four major functional modules: teaching, resources, announcement and user management. 
Teacher subsystem mainly includes three function modules: classroom, teaching and course project management. The specific functions involved are as follows, such as online answer, comprehensive evaluation, and information release.

Student subsystem mainly includes the following functional modules, namely assignments, browsing announcements, and online discussion. The corresponding functions mainly include score inquiry, announcement viewing, and online learning. Among them, online learning mainly includes three modules: basic course of music theory teaching, the teaching of Chinese and foreign modern music works, and the appreciation teaching of Chinese and foreign instrumental music works.

In order to make the function of the system more understandable and clearer, the function module is explained by the use case diagram. Figure 2 is the use case diagram of administrator subsystem.

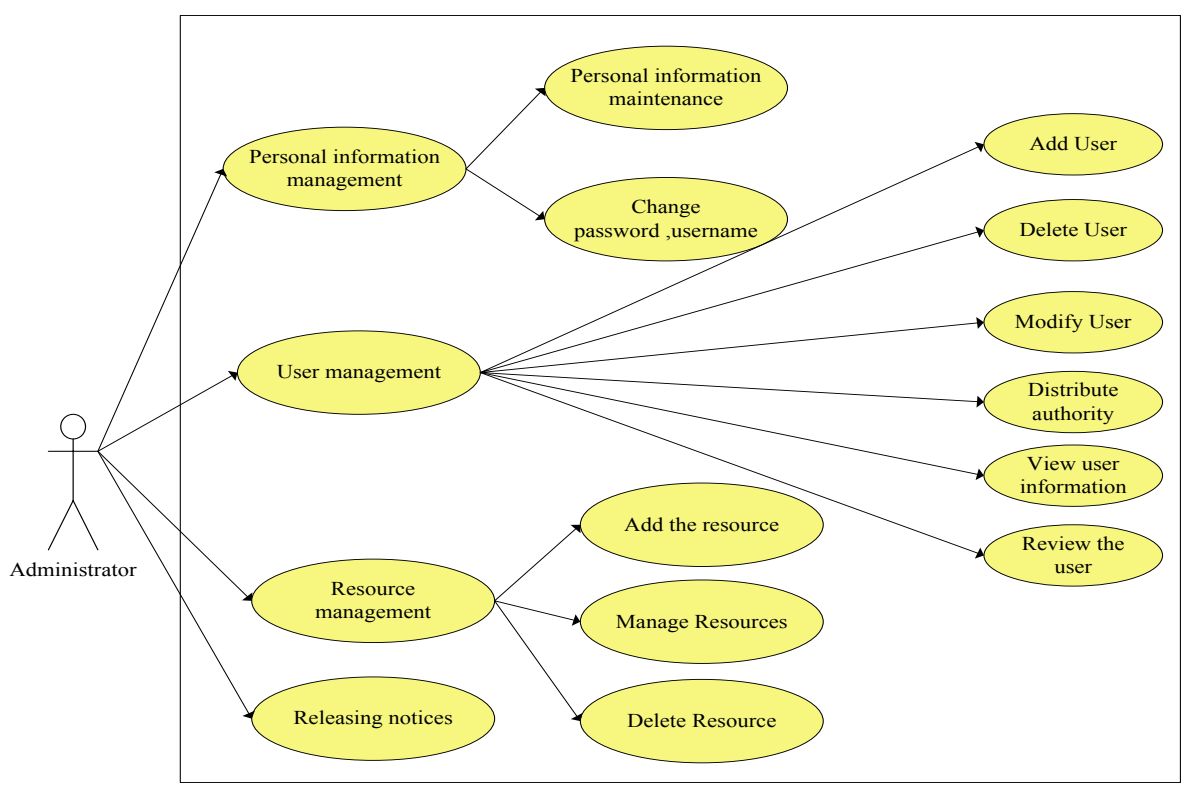

Fig. 2. Use case diagrams of administrator involvement

\section{$4 \quad$ Design of System}

\subsection{Design of function modules}

Based on the demand analysis of functions, this system is divided into seven major function modules to apply and manage the network teaching resources more effectively so that the music teaching model becomes more perfect and scientific. The functions and authority are set for all kinds of users so as to satisfy the requirements of users, as shown in Figure 3. 


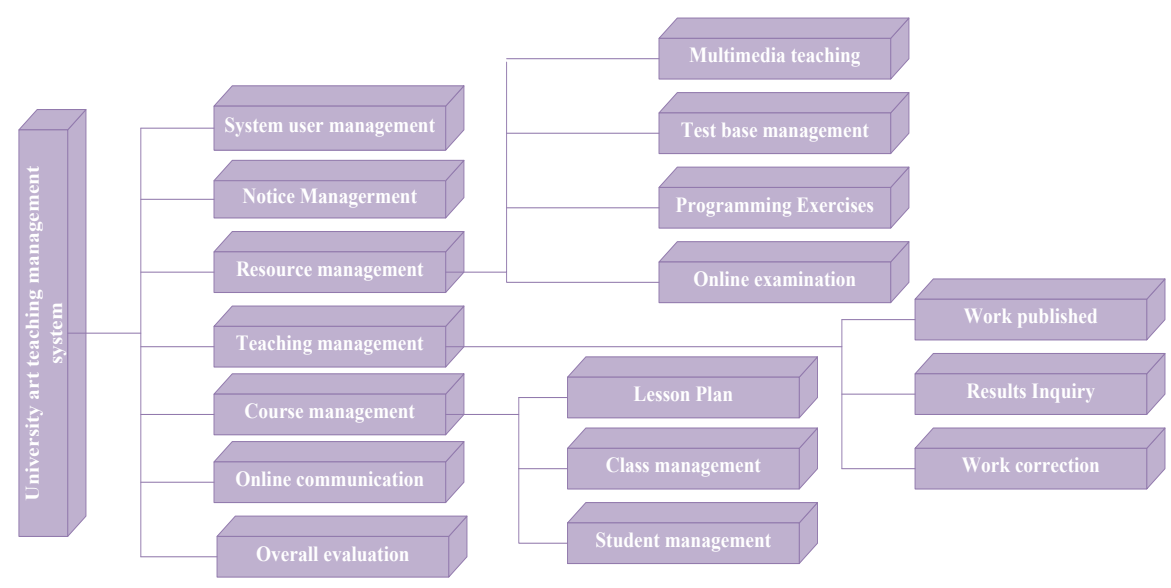

Fig. 3. System function diagram

Design of system user management module. This module has four main functions, such as user registration, user information viewing, modification and logout. Teachers and students can only view user information while administrator has access to all functions. In general, user registration is carried out by importing information in batches. For a small amount of information that needs to be perfected, the system administrator can modify it manually in a small range. For the information that has been expired and invalid in the system, administrators may clean up and log out in a timely manner. Figure 4 shows the specific flow chart of the user management module.

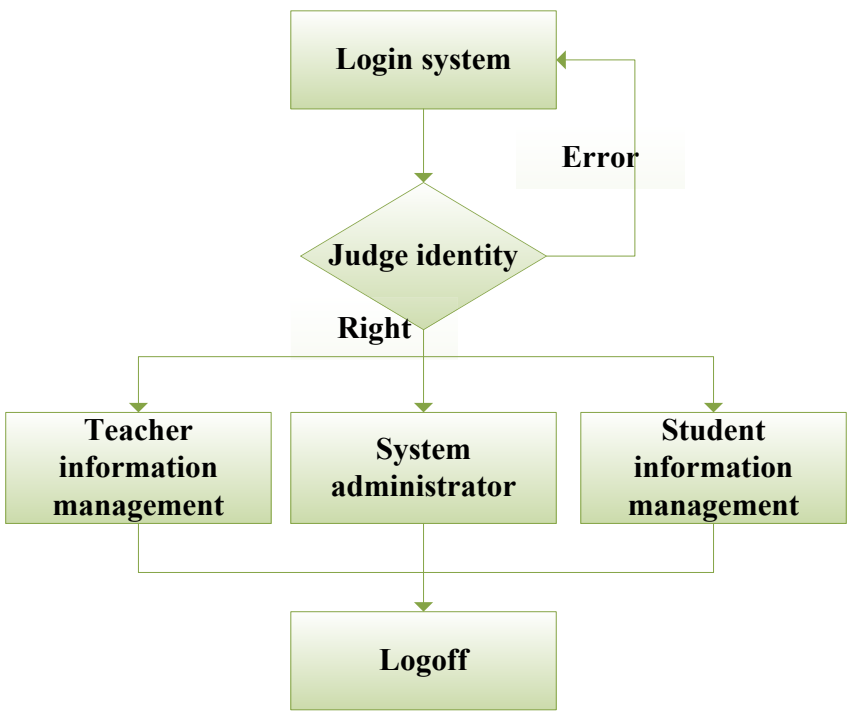

Fig. 4. Flow chart of user management module 
Design of announcement management module. This module mainly includes the following functions, namely, releasing, deleting, viewing and modifying the announcement that is divided into learning announcement and system announcement. Learning announcement is released by teachers while system announcement is issued by the administrator. In addition, the administrator can also perform operation such as deletion and modification for the announcement. Teachers are responsible for releasing learning announcement specifically including homework arrangement and class time adjustment and other contents. Students can leave messages and view the information, and teachers can modify, view and publish learning announcement. At the same time, for some malicious messages or expired information, the administrator can also delete.

Design of resource management module. This module specifically has the following functions, namely, data uploading, maintenance and examination database. First, art teachers upload various kinds of learning materials to wait for the system administrator's preliminary review, and the administrator judges whether to save according to whether the uploaded materials meet the actual teaching requirements. After these materials are saved, students can view and download the resources in the system freely according to their own learning requirements.

This module also has an extremely critical function, namely, test paper composition and examination database management. The part of music appreciation includes music theoretical basis, Chinese modern music works and music instrument works. In this system, each course has set up the corresponding examination database that involves explanation of nouns and choice. A teacher can form a complete test paper through manual or automatic form of test paper composition. Teachers shall define the number of test questions and form a complete test paper combine with random drawing and needs. Teachers are responsible for setting scores. At this time, through the application interface, students can view the complete test paper, and complete the test activity.

Design of teaching management module. This module is used to manage the network teaching security. At the beginning of the semester, the administrator makes proper arrangements for teachers and time based on the number of classes and students. Students and teacher users can view the course arrangement. If adjustment is required, teachers may give feedback to the administrator and the administrator carries out the change and second release of the teaching arrangement again based on the specific situation.

Design of curriculum management module. As a basic prototype of teaching plan, curriculum plan aims at guiding the curriculum practice, is used to describe the course project process. For the project course, it organizes in stages and provides reference delivery documents at all stages as a basis for acceptance of the project. Teachers can develop the evaluation strategies and curriculum plans to provide guidance for the development of courses. In particular, it relates to that following many modules, namely logical check, scoring, grouping, and project group progress viewing.

Design of online communication module. This module is mainly used to solve all kinds of problems encountered by students in network learning. The module can be divided into two blocks. One is that students can view all members of the class and conduct a separate exchange activity through the selection of part or one of them combine with the page. The other one is that students give their own viewpoints combined 
with the theme. After that, the theme will be represented on the online exchange page, and teachers will view it in a real time and raise opinions. In addition, students can also raise their own views on the issue. At the same time, when conducting learning activities, students may carry out communication for learning problems, as well as explore the topics they are interested in. The tense atmosphere of learning is regulated by the way of teaching through lively activities.

Design of comprehensive evaluation module. It defaults to the definition of project performance, and calculates the project performance through the corresponding calculation formula. Through the application of this module, the traditional scoring method of teacher scoring has been changed accordingly. At the same time, the results of intragroup evaluation and self-evaluation activities of students are added to the score as one of the important scoring items so that the result of scoring is fairer.

\subsection{Design of database}

In the development of this platform, it is necessary to conduct a more scientific design of database structure to ensure the integrity of data so that data can be stored more efficiently. When designing for this, we need to use the data structure to ensure the accuracy of the distribution of all database tables. If the data have the right structure, the program becomes simpler. As a backend database system, SQL Server 2000 is designed for 21 user tables. The corresponding role authority table is available in Table 1.

Table 1. Role permission list

\begin{tabular}{|c|c|c|c|c|c|}
\hline \multicolumn{6}{|c|}{ sys_role_right (Role permission list) } \\
\hline sys_role_right & $\begin{array}{c}\text { Field } \\
\text { description }\end{array}$ & $\begin{array}{c}\text { Data } \\
\text { type }\end{array}$ & $\begin{array}{c}\text { Null/ } \\
\text { Non-null }\end{array}$ & Windows default & $\begin{array}{c}\text { Constraint } \\
\text { condition }\end{array}$ \\
\hline rf_id & Serial number & Bigint & False & & Major key \\
\hline rf_role_id & Role number & Bigint & False & Foreign key \\
\hline rf_right_code & Access number & Varchar(50) & False & Foreign key \\
\hline Supplementary instruction & & & \\
\hline
\end{tabular}

The structure of the database requires that the input and output requirements of the information be met. The user requirement includes information browsing, information inquiring and information updating. In order to lay the foundation for the future design, the data needed at this time shall be detailed, namely, collection of information of the data structure and handling.

In the design process of above data table, the classification work can be carried out for the database table combined with the difference in type of stored information if it is related to the information associated with many foreign keys. Figure 5 shows E-R diagram corresponding to the system database. 


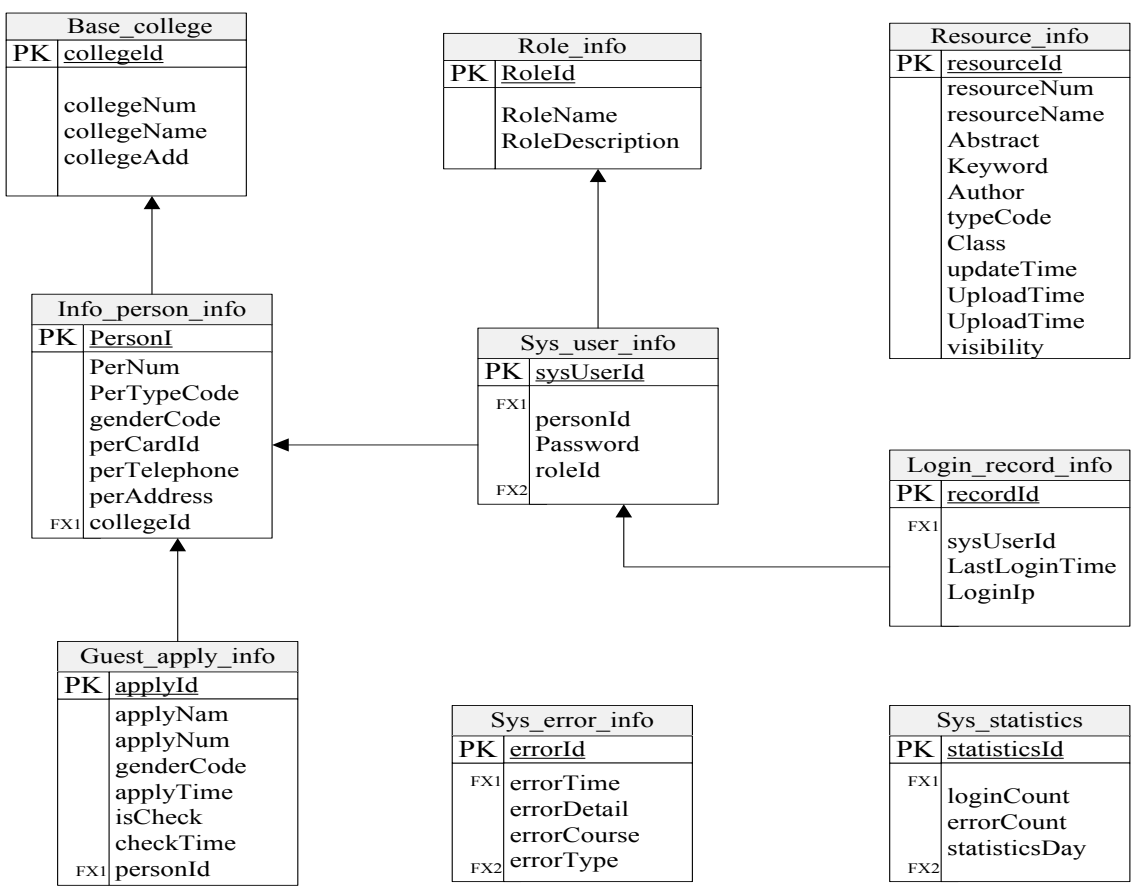

Fig. 5. ER diagram of the system database

\subsection{Design of network configuration}

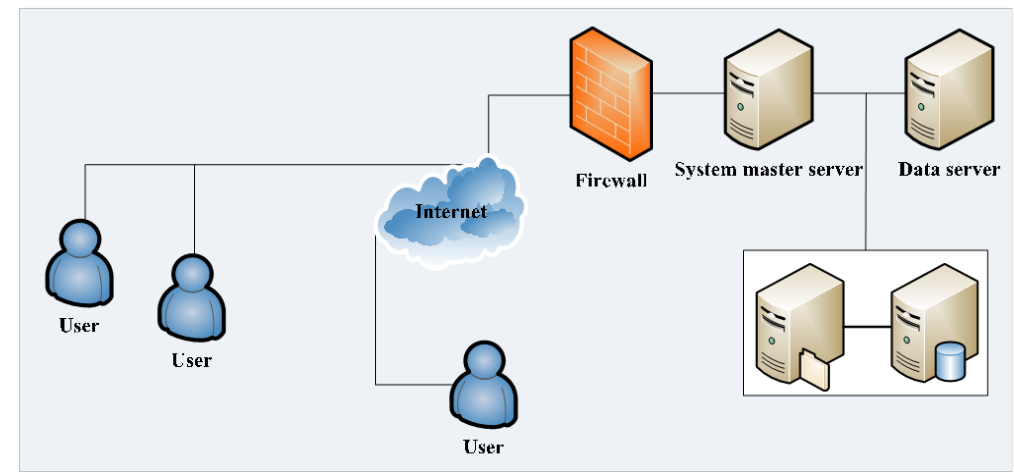

Fig. 6. System configuration diagram

When the system configures the three-layer $\mathrm{B} / \mathrm{S}$ architecture of $\mathrm{J} 2 \mathrm{EE}$, hardware needs to be invested, such as the addition of computer room and management machine to meet the configuration needs. In addition, it is necessary to connect through the network and access in the public network. Figure 6 is the corresponding network configuration diagram. 


\section{$5 \quad$ System Implementation and Testing}

\subsection{Implementation of the main modules of the system}

In the system, the most important is the resource management module. Combined with this module, students can query the information of class requirements, as well as check the test questions and assignments. Teachers can query all the teaching tasks and objectives of the current semester in the teaching management module, and then upload the required materials and courseware based on the resource management module. After entering the system smoothly, students can easily view the materials so that they can realize the training of self-learning ability. Figure 7 is the corresponding login page.

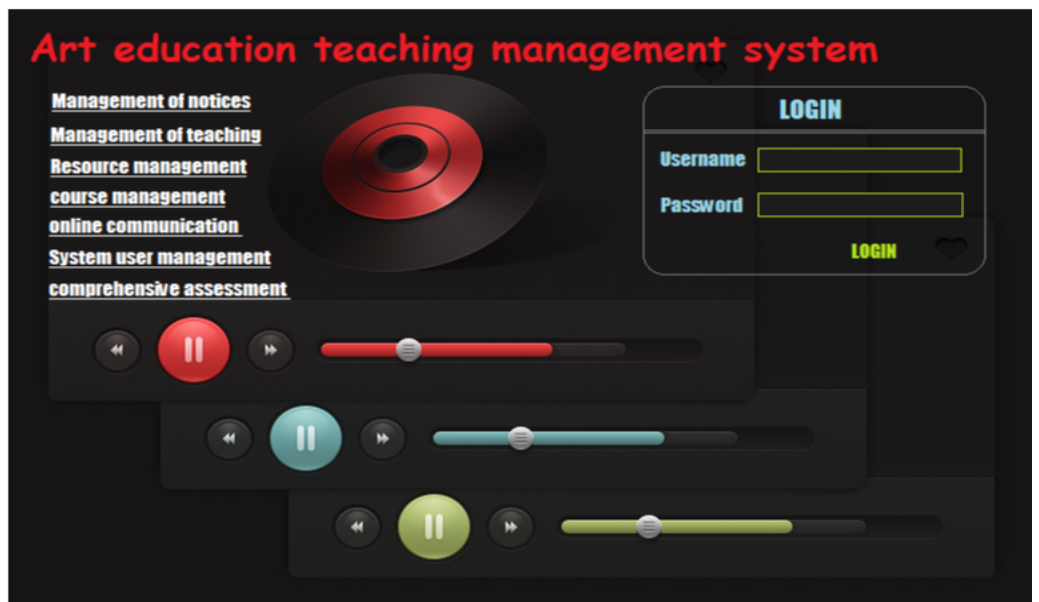

Fig. 7. University art education teaching management system login interface diagram

Some of the key codes in this module are as follows:

java.text.SimpleDateFormat $\mathrm{sdf}=$ new java.text.SimpleDateFormat("yyyyMMdd");

String fname $=$ sdf.format (new java.util.Date());

String upath = config.getServletContext().getRealPath("/upload/");

upath = upath + "\\" + fname;

FolderMaker fm = new FolderMaker();

boolean bmk $=$ fm. CreateFolder(upath);

String a = request.getServletPath();

upath = upath.replaceAll("IIII", "IIIIIIII");

upath = upath.replaceAll("/", "//");

if(upath.indexOf("/")>-1) \{

upath = upath + "//";

\}else \{

upath = upath + "IIII";

$$
\text { \} }
$$




\subsection{System testing}

The testing mainly involves the following aspects: the first is unit testing which tests the key project and source codes and checks whether the program module can make the specified function realized; the second is integration testing which conducts assembly testing mainly related to software architecture design; the third is confirmation testing that confirms whether the software is in conformity with the specifications, requirements, and software configuration; the fourth is to combine other system components and to complete the system software testing in the actual operation process. Table 2 shows the results of integration testing and the use case.

Table 2. Test cases and results of arts teaching management system

\begin{tabular}{|c|c|c|c|c|c|c|}
\hline No. & \begin{tabular}{|c|} 
Level1 \\
module
\end{tabular} & $\begin{array}{c}\text { Leve2 } \\
\text { module }\end{array}$ & $\begin{array}{l}\text { Use case de- } \\
\text { scription }\end{array}$ & Input data & Expected & $\begin{array}{c}\text { Correct or } \\
\text { not }\end{array}$ \\
\hline 1 & \multirow{4}{*}{ 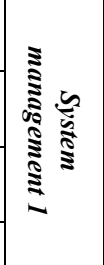 } & $\begin{array}{l}\text { User manage- } \\
\text { ment } 1.1\end{array}$ & Add a new user & $\begin{array}{l}\text { New username and } \\
\text { password }\end{array}$ & $\begin{array}{l}\text { New user suc- } \\
\text { ceeded }\end{array}$ & Correct \\
\hline 2 & & & $\begin{array}{l}\text { Change user } \\
\text { password }\end{array}$ & $\begin{array}{l}\text { New and old pass- } \\
\text { words }\end{array}$ & $\begin{array}{l}\text { Successful pass- } \\
\text { word modification }\end{array}$ & Correct \\
\hline 3 & & \multirow{2}{*}{$\begin{array}{l}\text { Role Manage- } \\
\text { ment } 1.2\end{array}$} & $\begin{array}{l}\text { Create a new } \\
\text { role }\end{array}$ & New role name & $\begin{array}{l}\text { Complete the addi- } \\
\text { tion of new roles }\end{array}$ & Correct \\
\hline 4 & & & Delete user roles & None & successfully delete & Correct \\
\hline 27 & \multirow{2}{*}{ 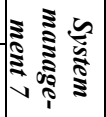 } & \multirow[b]{2}{*}{$\begin{array}{l}\text { Score } \\
\text { Inquiry }\end{array}$} & $\cdots \cdots$ & $\cdots \cdots$ & $\cdots \cdots$ & $\cdots \cdots$ \\
\hline 28 & & & Check results & $\begin{array}{l}\text { School year and term } \\
\text { information }\end{array}$ & $\begin{array}{l}\text { You can see the re- } \\
\text { sults of user queries }\end{array}$ & Correct \\
\hline
\end{tabular}

\section{Conclusions}

1. The research content of the subject, namely, the informatization of music teaching system, enables the R\&D of the art teaching system based on Java. This system can not only optimize the knowledge, but also use the teaching model and technology of project cooperation in the informatization.

2. Based on the $\mathrm{B} / \mathrm{S}$ framework, the teaching system is constructed for the application, which can greatly simplify the client side's work and improve the maintenance and R\&D efficiency.

3. The Struts architecture is designed through MVC pattern, which not only makes the maintainability of the system become more prominent, but also enhances the data processing ability.

4. Through the testing, it is found that the system is consistent with the expectation, which effectively improves the efficiency of art teaching management, develops art cause, as well as accelerates the reform of art education accordingly. 


\section{$7 \quad$ References}

[1] Ohchi, M., Furukawa, T., \& Tanaka, S. (2010). Development of education support sys-tem for numerical electromagnetic analysis based on server-client model using java. Electrical Engineering in Japan, 163(4), 8-17. https://doi.org/10.1002/eej.20377

[2] Hwang, G.H., Lee, Y.C., \& Wu, B.Y. (2005). A flexible failure-recovery model for workflow management systems. International Journal of Cooperative Information Systems, 14(01), 1-24. https://doi.org/10.1142/S0218843005000992

[3] Gray, J. (2004). A java-based approach for teaching principles of adaptive and evolv-able software. Science of Computer Programming, 53(1), 51-69. https://doi.org/10.1016/j.scico.2004.02.005

[4] Wu, X. (2014). Strategies for teaching java programming language to economics and management majors. Canadian Journal of Forest Research, 61(6), 703-710.

[5] Yıldırım, H., \& Büyüköztürk, Ş. (2018). Using the Delphi technique and focus-group interviews to determine item bias on the mathematics section of the level determina-tion exam for 2012. Educational Sciences: Theory \& Practice, 18(2), 447-470. https://doi.org/10.12738/estp.2018.2.0317

[6] Mzoughi, T., Herring, S. D., Foley, J. T., Morris, M. J., \& Gilbert, P. J. (2007). Webtop: a $3 \mathrm{~d}$ interactive system for teaching and learning optics. Computers \& Education, 49(1), 110129. https://doi.org/10.1016/j.compedu.2005.06.008

[7] Vesin, B., Ivanović, M., \& Budimac, Z. (2012). Protus 2.0: ontology-based semantic recommendation in programming tutoring system. Expert Systems with Applications, 39(15), 12229-12246. https://doi.org/10.1016/j.eswa.2012.04.052

[8] Liu, Z., Yu, H., Lim, E. P., Yin, M., Goh, H. L., \& Theng, Y. L. (2004). A java-based digital library portal for geography education. Science of Computer Programming, 53(1), 87-105. https://doi.org/10.1016/j.scico.2004.02.007

[9] Pradhan, A. R., Laefer, D. F., \& Rasdorf, W. J. (2007). Infrastructure management in-formation system framework requirements for disasters. Journal of Computing in Civ-il Engineering, 21(2), 90-101. https://doi.org/10.1061/(ASCE)0887-3801(2007)21:2(90)

[10] Higuera, T., Issarny, V., Banâtre, M., \& Parain, F. (2004). Memory management for realtime java: an efficient solut DOI:ion using hardware support*. Real-Time Systems, 26(1), 63-87. https://doi.org/10.1023/B:TIME.0000009306.22263.59

[11] Hauswirth, M., \& Adamoli, A. (2013). Teaching java programming with the informa clicker system. Science of Computer Programming, 78(5), 499-520. https://doi.org/10.1016/j.scico.2011.06.006

[12] Elnagar, A., \& Lulu, L. (2004). A global path planning java-based system for autono-mous mobile robots. Science of Computer Programming, 53(1), 107-122. https://doi.org/10.1016/i.scico.2004.02.008

[13] Filho, M. V. S., Bastos, J. C., \& Faria, M. V. C. (2001). Acetylcholinesterase response to salts in teaching the validation of toxicity bioindicatiors. Journal of Clinical In-vestigation, $1(3), 10$

[14] Loiseau, E., \& Laforcade, P. (2017). Specification of learning management system-centered graphical instructional design languages: a dsm experimentation about the moodle platform. Journal of Hepatology, 60(1), 2289-2298.

[15] Rosenheim, A., \& Jahn, H. (2010). Ueber einige neue verbindungen der oxalsäure. European Journal of Inorganic Chemistry, 26(2), 1191-1194.

[16] Wang, S., \& Sun, J. (2001). A framework design of workflow management system with java rmi. Acm Sigplan Notices, 36(9), 86-93. https://doi.org/10.1145/609769.609783 
[17] Boyle, J., Rovira, H., Cavnor, C., Burdick, D., Killcoyne, S., \& Shmulevich, I. (2009). Adaptable data management for systems biology investigations. Bmc Bioinformatics, 10(1), 1-16. https://doi.org/10.1186/1471-2105-10-79

[18] Smith, S. G. (1998). From mainframes to the web: 1998 george c. pimentel award. Journal of Chemical Education, 75(9), 1080-1087. https://doi.org/10.1021/ed075p1080

[19] Javani, N., Dincer, I., Naterer, G. F., \& Yilbas, B. S. (2014). Exergy analysis and opti-mization of a thermal management system with phase change material for hybrid elec-tric vehicles. Applied Thermal Engineering, 64(1-2), 471-482. https://doi.org/10.1016/j.applthermaleng.2013.11.053

[20] Tennyson, R., \& Sisk, M. (2011). A problem-solving approach to management of in-structional systems design. Behaviour \& Information Technology, 30(1), 3-12. https://doi.org/10.1080/0144929X.2010.490958

\section{Author}

Xuchun Chen, male (1968.12 --), Master, Associate Professor, School of Modern International Design and Art, Chongqing Technology and Business University, Master's tutor. Main research directions: Fine Arts, Design.

In recent years, he has mainly engaged in the teaching of graphic design. The main courses include graphic advertising design, illustration design, VI design, Chinese and Western characters and layout design research. He is committed to the study of traditional art and painting art. In recent years, he has mainly studied Chinese Han Dynasty art, presided over two provincial and ministerial-level topics, published two monographs, and published more than 10 papers.

Article submitted 23 July 2018. Resubmitted 12 August 2018. Final acceptance 10 September 2018. Final version published as submitted by the author. 